\title{
Stimulus competition as a function of varying stimulus meaningfulness ${ }^{1}$
}

ROBERT L. SOLSO and EILEEN S. TRAFIMOW, Loyola University, Chicago, Ill. 60626

This study examined the effects of varying the meaningfulness of stimuli within a compound stimulus. Stimulus competition, as a function of increased similarity of stimulus meaningfulness, retarded acquisition. The results were interpreted in terms of stimulus selection as a separate stage in paired-associate learning.

The fact that functional stimuli are selected from within compound stimuli has been well documented within the last several years. An analysis of the factors that determine stimulus selection has identified some specific conditions that enhance the selection of one cue over another. These include the position of one verbal element in relationship to another (Cohen \& Musgrave, 1964), the degree of formal stimulus similarity of items within a list (Cohen \& Musgrave, 1966), and the distinctiveness of one stimulus contrasted with another's (Cohen \& Musgrave, 1966; Newman \& Taylor, 1963). The most frequently investigated factor involved in functional stimulus selection has been the relative meaningfulness of stimuli within a compound. Considerable evidence has been reported by Cohen \& Musgrave (1964), James \& Greeno (1967), Solso (1968), and Underwood, Ham, \& Ekstrand (1962) to support the contention that functional stimulus selection is largely determined by the meaningfulness of stimuli.

Paired-associate learning, using compound stimuli, has also revealed that acquisition is slower with two stimuli than with only one highly meaningful stimulus. This has been clearly exhibited under learning conditions utilizing two verbal elements (Musgrave, 1962) and under conditions utilizing a verbal stimulus and a color stimulus (Solso, 1968). Several hypotheses have been suggested to account for this phenomenon. Greeno \& Horowitz (1968) and Solso (1968), working independently, suggested that Ss may attend to one element in the compound stimulus and tentatively use it as a functional stimulus but later abandon it in favor of the other element in the compound stimulus. The net result of this early vacillation may manifest itself as a retardation in the learning of the entire paired-associate list. In addition, Solso (1968) has suggested a hypothesis of stimulus competition based on a backward learning or an R-S model. This hypothesis has an analogue in the response competition of the A-B, A-C transfer paradigm, in which associative interference of the B component in A-C transfer is frequently observed.

A final preliminary observation is that there may be a direct relationship between the degree to which stimuli within a compound stimulus approximate each other in terms of meaningfulness and stimulus competition. Hence, single-stimulus conditions virtually eliminate stimulus competition, but two equally desirable-or equally meaningful-stimuli of widely diverse meaningfulness may compete to a much lesser extent. The present experiment was designed to test the notion that degree of stimulus competition is a function of the relative meaningfulness of stimuli within a compound stimulus.

\section{METHOD}

The overall design involved the presentation of paired-associate lists composed of compound stimuli of increasing divergency of meaningfulness to separate groups of Ss.

\section{Lists}

Five levels of stimulus conditions were used. The first level consisted of nine paired associates, with both stimuli of the compound stimulus selected from $100 \% \mathrm{~A} \cdot \mathrm{V}$, the second from $100 \% \dot{A} \cdot \mathrm{V}$ and $75 \% \mathrm{~A} \cdot \mathrm{V}, 100 \% \mathrm{~A} \cdot \mathrm{V}$, and $50 \% \mathrm{~A} \cdot \mathrm{V}$, and $100 \% \mathrm{~A} \cdot \mathrm{V}$ and $25 \% \mathrm{~A}-\mathrm{V}$, respectively. The fifth level consisted of single stimuli selected from $100 \% \mathrm{~A}-\mathrm{V}$. Responses were single digits from 1 to 9 . For each level, two lists composed as described above were used to reduce the possibility of varying difficulty. Half the Ss received one list, while the other half received the second list within each level. Three random orders were used at all levels with 2:2-sec-rate and 4-sec-intertrial-interval anticipation learning. The items were presented on a Stowe memory drum.

\section{Subjects}

A total of 100 undergraduate students, randomly assigned to test levels, served as Ss. Thus, each of the five levels was composed of $20 \mathrm{Ss}$, with $10 \mathrm{Ss}$ in each of the two list conditions. Approximately equal numbers of males and females were used within each level.

\section{Procedure}

Each $\mathbf{S}$ was tested individually in a quiet experimental room. Standard paired-associate instructions were read to each S. Ss within compound-stimulus conditions were informed that both stimuli would be consistently paired with their response term, and care was taken not to bias the Ss in favor of either stimulus. Ss continued practice until one perfect trial was attained. Following acquisition, a test of free recall of stimuli was administered.

\section{RESULTS}

The overall means and standard deviations for the five stimulus levels are presented in Table 1. The overall variation due to stimulus levels was significant, with $F(4,95)=3.75, p<.01$. The means of the two forms within each stimulus level were nearly identical. (The relationship between varying stimulus meaningfulness and acquisition rate are represented in Fig. 1.) Stimulus competition, especially between two highly meaningful stimuli, is apparent in this figure in contrast to the single-stimulus condition. Specific comparisons were made between each stimulus level by means of Duncan's new multiple-range test. This test indicated that the mean value of the $100 \%-100 \%$ compound-stimulus condition and the $100 \%$ simple-stimulus condition were significantly different at the .01 level. The mean value of the $100 \%-100 \%$ group was 16.25 ; the mean value of the $100 \%$ group was 10.40. Although the specific comparison between other means did not yield statistically significant data, it is noted that the three middle conditions (100\%-75\%, 100\%-50\%, and 100\%-25\%), in which it was anticipated that stimulus competition would be moderate, produced means of nearly identical magnitude. They were $12.30,13.85$, and 13.05. The results appear to reflect three levels of acquisition rates: slow acquisition for the 100\%-100\% group, moderate acquisition for the three middle groups, and rapid acquisition for the simple-stimulus condition.

The free recall of stimuli indicated an increase in recall of highly meaningful stimuli as a concomitant of stimulus disparity. Conversely, recall of low meaningful stimuli decreased as lower meaningful stimuli were paired with highly meaningful stimuli. (These relationships are presented in Fig. 2.) Because of the

Table 1

Mean Trials to Criterion for Stimulus Levels

\begin{tabular}{lccccc}
\hline Meaningfulness & $100 \%$ & $100 \%$ & $100 \%$ & $100 \%$ & $100 \%$ \\
of Stimuli & $100 \%$ & $75 \%$ & $50 \%$ & $25 \%$ & \\
Mean Trials to Criterion & 16.25 & 12.30 & 13.85 & 13.05 & 10.40 \\
Standard Deviation & 5.3 & 6.2 & 5.4 & 4.0 & 5.7 \\
\hline
\end{tabular}




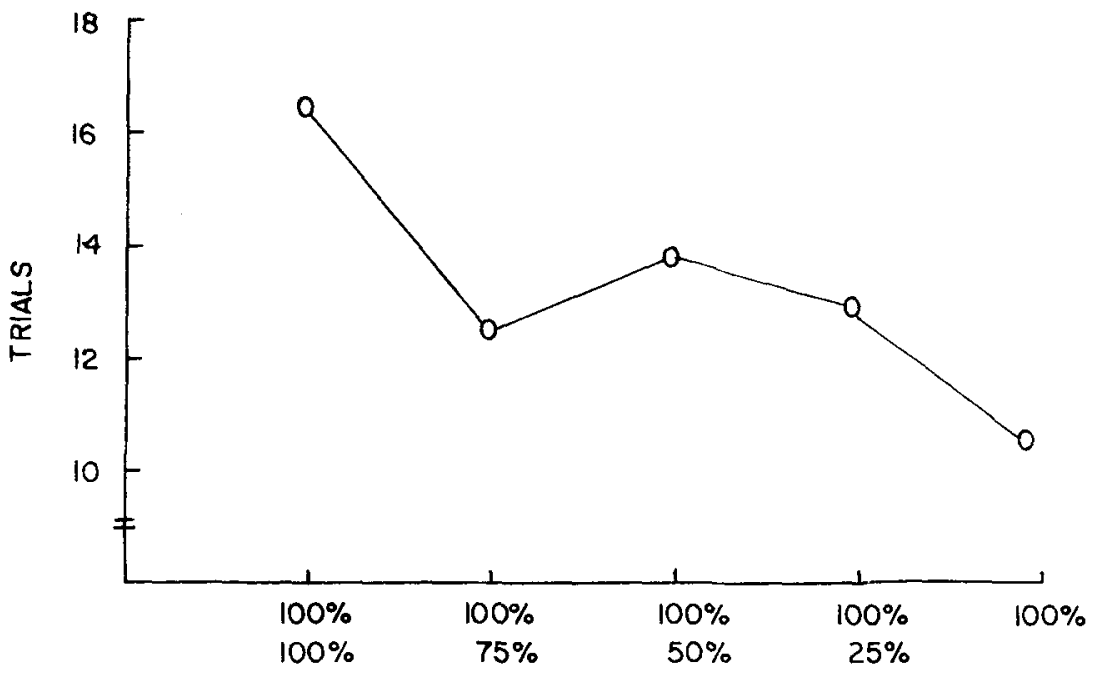

MEANINGFULNESS OF STIMULI

increase in recall of highly meaningful stimuli, it can be inferred that Ss within this study were selecting these elements as a functional stimulus.

\section{DISCUSSION}

Two theoretical considerations were examined in this study: (1) functional stimulus selection as a function of meaningfulness and (2) stimulus competition as a function of increased

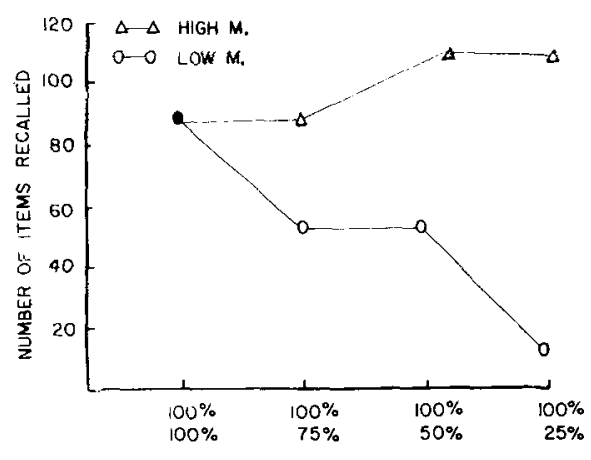

MEANINGFULNESS OF STIMULI

Fig. 2. Total number of items recalled as a function of meaningfulness of stimuli.
Fig. 1. Mean trials to criteria as a function of meaningfulness of stimuli.

is suggested that the S's attention to stimuli and visual search of stimuli for functional stimulus selection is a significant and identifiable stage of paired-associate learning. As the perceptual field becomes more cluttered and as cue selection becomes more perplexing, greater time must be devoted to stimulus selection with less time devoted to response acquisition and to $S-R$ association. The net result of stimulus competition may be retarded acquisition rates. The results reported in this paper and in other studies indicate that retarded acquisition is a concomitant of stimulus competition.

\section{REFERENCES}

COHEN, J. C., \& MUSGRAVE, B. S. Effect of meaningfulness on cue selection in verbal paired-associate learning. Journal of Experimental Psychology, 1964, 68, 282-291.

COHEN, J. C., \& MUSGRAVE, B. S. Effects of formal similarity on cue selection in verbal paired-associate learning. Journal of Experimental Psychology, 1966, 71, 829-838.

GREENO, J. G., \& HOROWITZ, L. M. On unitizing a compound stimulus. Journal of Verbal Learning \& Verbal Behavior, 1968, ?, 913-917.

JAMES, C. T., \& GREENO, J. G. Stimulus selection at different stages of paired-associate learning. Journal of Experimental Psychology, 1967, 74, 75-83.

MUSGRAVE, B. S. The effect of nonsense-sy llable compound stimuli on latency in a verbal paired-associate task. Joumal of Experimental Psychology, 1962, 63, 499-504.

NEWMAN, S. E., \& TAYLOR, L. R. Context effects in paired-associate learning as a function of element-sharing among stimulus terms. Journal of Verbal Learning \& Verbal Behavior, 1963, 1, 243-249.

SOLSO, R. L. Functional stimulus selection as related to color versus verbal stimuli. Journal of Experimental Psychology, 1968, 78, 382-387.

UNDERWOOD, B. J., HAM, M., \& EKSTRAND,

$B$. Cue selection in paired-associate learning. Journal of Experimental Psychology, 1962, $64,405-409$.

\section{NOTE}

1. A section of this paper was presented at the Midwestern Psychological Association meeting, May 1969, Chicago, Ill. 